\title{
A ortotanásia sob a ótica dos direitos humanos
} Ortotanasia under the human rights view Ortotanasia bajo la vista de derechos humanos

Heitor Romero Marques ${ }^{1}$ Amanda Lúcio da Silva Gonçalves ${ }^{2}$ Luiz André de Carvalho Macena ${ }^{3}$

${ }^{1}$ Doutor em Desarrollo Local Y Planteamiento Territorial pela Universidad Complutense de Madrid. Docente na Universidade Católica Dom Bosco (UCDB) na graduação e na pós-graduação. E-mail: heiroma@ucdb.br, ORCID: http://orcid.org/0000-0003-0093-1617

${ }^{2}$ Graduada em Direito pela Universidade Católica Dom Bosco. E-mail: amanda_Isg1@hotmail.com, ORCID: http://orcid.org/0000-0001-5394-4265

${ }^{3}$ Mestre em Direito - área de concentração em Empreendimentos Econômicos, Desenvolvimento e Mudança Social. Especialista em Direito

Civil e Processual Civil. Advogado e docente do curso de Direito da Universidade Católica Dom Bosco (UCDB). E-mail: macena@ucdb.br, ORCID: http://orcid.org/0000-0002-4865-9133 
Resumo: O presente artigo foi realizado mediante revisão bibliográfica, utilizando-se da tendência hipotético-dedutiva e do procedimento analítico-sintético, enquadrando-se na linha na função social do direito e interculturalidade, na subárea de direitos sociais e políticas públicas, tendo como objetivo principal o estudo da ortotanásia no ponto de vista dos Direitos Humanos e do ordenamento jurídico brasileiro, analisando sua recepção, as possíveis implicações legais e se ela pode ser considerada um fim digno aos pacientes terminais. Essa discussão faz-se necessária, pois o paciente terminal merece ter sua autonomia, liberdade e dignidade respeitados no fim da vida. Dessa forma, a presente pesquisa demonstrou que houve uma recepção da ortotanásia pelo ordenamento jurídico brasileiro, contudo a carência de regulamentação apropriada proporciona insegurança e incerteza jurídica aos médicos acerca de sua prática. Verificou-se que a ortotanásia possui resguardo nos direitos humanos, ao respeitar a dignidade da pessoa humana em todos os seus traços. Ao final, foi possível concluir que, em razão de possibilitar que o enfermo tenha o poder de escolher como vai morrer, proporcionando qualidade de vida, cuidados paliativos e bem-estar, a ortotanásia pode ser considerada um fim digno.

Palavras-chave: ortotanásia; direitos humanos; dignidade da pessoa humana.

Abstract: Through bibliographic review, hypothetico-deductive and analytic-synthetic methods, inserted in law and interculturality's social purpose, on the social law and public politics subarea, this article aims the study of orthothanasia on the Human Rights point of view and the analysis of orthothanasia in Brazil, demonstrating its reception by the Brazilian Legal System and its possible legal implications, and also if this practice can be considered as a dignified end to terminal patients. This debate has become necessary because terminal patients deserve to have their autonomy, liberty and dignity respected in the end of life. Therefore, this research showed that the Brazilian Legal System accepted orthothanasia, however the lack of appropriate regulation makes doctors feel unsafe and uncertain about practicing orthothanasia. The research also showed that orthothanasia respects Human Rights by respecting the Human Being Dignity on all its traces. By the end of the research, considering that it enables the patient to decide how he will die, it was possible to conclude that orthothanasia can be recognized as a dignified end of life.

Keywords: orthothanasia; human rights; human being dignity.

Resumen: O presente artigo foi realizado mediante revisão bibliográfica, utilizando-se da tendência hipotético-dedutiva e do procedimento analítico-sintético, enquadrando-se na linha da função social do direito e interculturalidade, na subárea de direitos sociais e políticas públicas, tendo como objetivo principal o estudo da ortotanásia no ponto de vista dos Direitos Humanos e do ordenamento jurídico brasileiro, analisando sua recepção, as possíveis implicações legais e se ela pode ser considerada um fim digno aos pacientes terminais. Esta discusión es necesaria porque el paciente terminal merece que se respete su autonomía, libertad y dignidad al final de la vida. Por lo tanto, la presente investigación demostró que la ortotanasia fue recibida por el sistema legal brasileño, sin embargo, la falta de una regulación adecuada proporciona inseguridad e incertidumbre legal a los médicos sobre su práctica. Se descubrió que la ortotanasia tiene protección para los derechos humanos, al respetar la dignidad de la persona humana en todas sus características. Al final, fue posible concluir que, dado que le permite al paciente tener el poder de elegir cómo va a morir, brindando calidad de vida, cuidados paliativos y bienestar, la ortotanasia puede considerarse un final digno.

Palabras clave: ortotanasia; derechos humanos; dignidad de la persona humana. 


\section{INTRODUÇÃO}

Diante do sofrimento experimentado por pacientes com doença em estágio terminal, vários métodos com a intenção de diminuir ou cessar o tormento vêm à tona, como a eutanásia, a distanásia e a ortotanásia.

Apresentando-se como um método de morte destes pacientes terminais, a ortotanásia é objeto de grande discussão no âmbito jurídico brasileiro, desde sua aparição por meio da Resolução n. 1.805/2006 do Conselho Federal de Medicina (CFM), trazendo o questionamento acerca de sua conformidade com o ordenamento jurídico brasileiro, bem como com os Direitos Humanos.

A presente pesquisa, mediante revisão bibliográfica e valendo-se do método hipotético-dedutivo, utiliza como partida a hipótese de que a ortotanásia não afronta o princípio da dignidade da pessoa humana, sendo considerada uma forma de morte digna aos pacientes terminais que se encontram em situação de muita dor e sofrimento, sem antecipar a morte natural e nem prolongar a vida precária. Adianta-se que a pesquisa se enquadra na linha dois de pesquisa do Núcleo de Pesquisa e Monografia Jurídica (NUPEJU), qual seja a função social do direito e interculturalidade, na subárea de direitos sociais e políticas públicas.

A lógica analítico-sintética foi adotada na presente pesquisa, como forma de possibilitar sínteses conclusivas acerca do tema para sua melhor compreensão. Sendo assim, foram feitas análises minuciosas e detalhadas das teses e dissertações a partir do Catálogo de Teses da CAPES, bem como a revisão bibliográfica de livros relacionados ao tema.

O intento da pesquisadora é o de analisar e compreender a situação da ortotanásia com relação aos direitos humanos, bem como se há uma recepção deste instituto no ordenamento jurídico brasileiro e se ele pode ser considerado um fim digno aos pacientes terminais.

\section{CONCEITUAÇÃO E BREVE HISTÓRICO}

Para tratar acerca da ortotanásia, faz-se necessário compreender alguns conceitos que fundamentam o tema e têm relação direta com ele, quais sejam a bioética, as diretivas antecipadas de vontade e o biodireito. 
A bioética pode ser entendida como o estudo que combina a ética com as ciências biológicas, conforme os avanços e as evoluções da tecnologia. Tem o objetivo de compreender os avanços biológicos e biotecnológicos, bem como as relações humanas com as ciências biológicas, de um ponto de vista ético e moral. Assim conceitua a Encyclopedia of bioethics (1995, p. XXI): "[...] estudo sistemático das dimensões morais das ciências da vida e do cuidado da saúde, utilizando uma variedade de metodologias éticas num contexto multidisciplinar".

Diante da preocupação com a qualidade da vida humana, da necessidade de um guia para o bom desempenho dos médicos e outros profissionais da saúde, bem como de acompanhar o progresso científico, biomédico e biotecnológico, o termo bioética passou a ser considerado como a ética da medicina e da ciência.

Insta salientar que a bioética está diretamente relacionada com a dignidade humana, condicionando os praticantes de medicina a respeitar a vida digna. De acordo com Diniz (2007), o respeito aos seres humanos em todas as suas fases da vida só é alcançado se houver respeito à sua dignidade, ou seja, a vida humana não se trata apenas de uma sobrevivência física, mas de uma vida digna. Dessa forma, a bioética e o biodireito devem preocupar-se com a dignidade humana e tratá-la como um princípio ético em que a biomedicina está sujeita a seguir.

Existem princípios básicos que regem a bioética, norteando a ação dos profissionais de saúde, quais sejam: o princípio da autonomia, o princípio da beneficência, o princípio da não maleficência e o princípio da justiça.

O princípio da autonomia significa que os profissionais de saúde têm o dever de agir levando em consideração a vontade de seus pacientes ou representantes destes, bem como informando-os corretamente da situação em que se encontram e de suas opções, riscos e vantagens, de forma a possibilitar que realizem um consentimento plenamente consciente e possuam uma liberdade de escolha sobre suas vidas.

Inserido no contexto do princípio da autonomia, há ainda a possibilidade de utilização do instrumento de diretivas antecipadas de vontade, ou testamento vital, que se apresenta como uma forma de organização e programação prévia de cuidados médicos pelo paciente, permitindo que 
ele manifeste expressamente sua vontade acerca dos tratamentos a serem ou não realizados. Dessa forma, de acordo com Gonçalves (2019, p. 324), o testamento vital constitui:

[...] uma declaração unilateral de vontade em que a pessoa manifesta o desejo de ser submetida a determinado tratamento, na hipótese de se encontrar doente, em estado incurável ou terminal, ou apenas declara que não deseja ser submetida a nenhum procedimento que evite a sua morte.

O testamento vital, inclusive, mostra-se como uma alternativa para que o indivíduo exprima suas vontades no caso de sua incapacidade sobrevier, evitando o ferimento de sua autonomia e livre consentimento nas situações médicas, tendo em vista a grande preocupação acerca da tomada de decisões por outra pessoa que não o enfermo.

O princípio da beneficência é baseado na responsabilidade dos profissionais de saúde em atender seus pacientes, com o objetivo principal de alcançar o seu bem-estar, e condiz com o princípio da não maleficência, que, por sua vez, trata da obrigação de não causar danos aos pacientes de modo premeditado ou voluntário.

No que Ihe diz respeito, o princípio da justiça possui relação com o dever de imparcialidade atribuído ao profissional de saúde, atrelado ao tratamento a todos com igualdade. De acordo com Almeida (2000, p. 8): "[...] o princípio da justiça rege que ela deve ser distributiva, ou seja, que todos devem ter acesso aos procedimentos médicos necessários, independentemente de sua situação econômica".

O conjunto de princípios e diretrizes é utilizado como base para o biodireito, que, por sua vez, surgiu da necessidade de normatizar, positivar e regular as condutas dos indivíduos nas práticas de medicina e biologia, tornando exigíveis as condutas da bioética, bem como atuando em conjunto com ela. Diniz (2007) conceitua o biodireito como o estudo jurídico que utiliza a bioética e a biogenética como fontes principais e tem como propósito fundamental a vida, demonstrando que existem limitações à verdade científica com relação à ética e ao direito, de modo que o progresso e a verdade científica devem respeitar os limites jurídicos e éticos, não podendo acobertar crimes contra a dignidade humana, por exemplo. 
O biodireito atua de forma a evitar abuso por parte dos praticantes da medicina e biologia, garantindo a evolução das ciências e da biotecnologia em conformidade com a dignidade da pessoa humana. Desse modo, Regina Lúcia Fiúza Sauwen apud Diniz (2010, p. 7-8) afirma que "[...] a esfera do Biodireito compreende o caminhar sobre o tênue limite entre o respeito às liberdades individuais e a coibição de abusos contra o indivíduo ou contra a espécie humana".

Além da bioética, diretivas antecipadas de vontade e biodireito, a conceituação de algumas formas de terminar a vida, como a eutanásia, a distanásia e a própria ortotanásia, faz-se indispensável para a melhor compreensão do tema.

O termo eutanásia advém dos vocábulos gregos eu: boa, e thánatos: morte, o que significa "boa morte", na forma literal, no sentido de morte sem dor ou sem sofrimento e foi inicialmente utilizado em 1623, por Francis Bacon, em sua obra Historia vitae et mortis. Lopes, Lima e Santoro (2018) entendem a eutanásia como o ato de extinguir a vida de um indivíduo acometido por enfermidade incurável que lhe cause dor e sofrimento, motivado pela piedade e em benefício do enfermo, ou seja, o autor da eutanásia assim o faz em razão da compaixão para com o indivíduo e com a intenção de fazer cessar a dor e o sofrimento causados pela enfermidade, sendo este um fator que diferencia a eutanásia do homicídio simples.

A eutanásia é considerada como um dos modos de morte digna, sendo utilizada principalmente nos casos de pacientes com doenças terminais - apesar de não se limitar a esses casos, estendendo-se às situações de recém-nascidos com malformações congênitas e pacientes em estado vegetativo -, com o intuito de fazer cessar a dor e o sofrimento trazidos pelas doenças terminais, sendo caracterizada pela compaixão.

Os defensores da eutanásia têm como argumento para sua utilização o princípio da qualidade de vida, no sentido de que a vida não vale a pena ser vivida se não estiver dotada de qualidade, remetendo à afirmação de Sócrates de que "O que vale não é o viver, mas o viver bem".

Salienta-se que a prática da eutanásia não é permitida pelo ordenamento jurídico brasileiro, que não descaracteriza o homicídio em razão de compaixão ou piedade, ou seja, mesmo que o indivíduo praticante houver 
sido motivado pela compaixão diante de uma doença terminal, ele incidirá nas penas do Art. 121 do Código Penal Brasileiro.

Passando para a distanásia, do grego dis: mal e thánatos: morte, seu significado etimológico é "morte mal feita", "morte errada" ou "morte defeituosa". Assim, conforme Diniz (2007, p. 353): “[...] trata-se do prolongamento exagerado da morte de um paciente terminal ou tratamento inútil. Não visa prolongar a vida, mas sim o processo de morte".

A distanásia caracteriza-se pela utilização de métodos e tratamentos terapêuticos com a única intenção de prolongar a vida do paciente acometido por doença terminal e incurável, não se atentando à qualidade de vida deste, que passa a viver por mais tempo, porém em uma situação precária e desumana. Sua prática iniciou-se com o Código Deontológico Médico de 1931, em que a medicina se preocupava apenas com que o paciente sobrevivesse e se mantivesse vivo, independentemente de uma condição de vida e saúde boas.

Ao longo do tempo, a preocupação com a qualidade de vida e saúde do paciente passou a ser maior, e a prática da distanásia deve ser entendida como vedada no Brasil, pois contraria os princípios da bioética, bem como a dignidade da pessoa humana, prevista no Art. 5으, inciso III da Constituição Federal de 1988. Acerca disso, Vieira (2009) diz que a distanásia contraria a dignidade, pelo que deve ser evitada, exceto se o paciente livremente manifeste sua vontade nesse sentido, requerendo a aplicação de todos os meios terapêuticos possíveis para prolongar sua vida, ainda que esta seja mantida de forma totalmente mecânica.

A ortotanásia, no entanto, do grego orto: certa e thánatos: morte, significa "morte certa", ou seja, morte no momento em que deveria ser, sem acelerá-la (eutanásia), mas também sem prolongar a vida de baixa qualidade (distanásia). Assim entende Cabette (2013), ao afirmar que a ortotanásia seria a morte da maneira certa, evitando ou suprimindo os tratamentos fúteis, extraordinários ou desproporcionais diante do processo iminente da morte do paciente, que não é provocado, tampouco tentado.

Essa forma terminativa da vida é considerada digna, possibilitando ao paciente acometido por doença terminal e irreversível uma morte natural e humanizada. Caracteriza-se pela utilização de cuidados paliativos pelos 
profissionais de saúde que aliviem a dor e o sofrimento do paciente, bem como pela omissão ou interrupção de tratamentos que prolonguem a vida sem que haja a cura, priorizando seu bem-estar e sua saúde durante o processo natural da morte, de acordo com as vontades do enfermo.

A prática da ortotanásia está autorizada pelo Código de Ética Médica e pela Resolução n. 1.805/2006 do Conselho Federal de Medicina, trazendo limites e requisitos para sua realização. Dentre tais requisitos, estão: a instalação do processo da morte inevitável, a autorização por parte do paciente terminal ou de seus familiares e o exercício dos médicos com o objetivo único de proporcionar o bem-estar do paciente, cuidando-o com tratamentos paliativos para amenizar ou aliviar suas dores e sofrimentos. A necessidade de tais limites e condições se dá para evitar que a atuação dos médicos implique omissão de cuidado e socorro, ou em eutanásia, uma vez que, havendo a possibilidade de cura, o médico deverá prosseguir com o tratamento para este fim.

Além do acima exposto, os tratamentos paliativos a serem realizados nos pacientes nas situações de ortotanásia estão instruídos no Manual de Cuidados Paliativos e, segundo a Organização Mundial de Saúde (OMS), incluem a atuação conjunta de médicos, enfermeiros, profissionais da saúde mental e assistentes sociais, com o intuito de proporcionar um suporte psicológico, físico, psicossocial e espiritual aos pacientes, em prol de uma boa qualidade de vida nesse momento delicado.

\section{A ORTOTANÁSIA NO BRASIL}

No Brasil, a ortotanásia é alvo de diversas discussões jurídicas acerca de sua conformidade, regulamentação e aplicação, relacionado ao ordenamento jurídico pátrio como um todo. Dessa forma, deve-se realizar uma análise sumária das Resoluções n. 1.805/2006 e n. 1.995/2012 editadas pelo Conselho Federal de Medicina, que tratam sobre a prática de ortotanásia e as diretivas antecipadas da vontade dos pacientes, bem como do Código Penal Brasileiro a respeito da ortotanásia e suas implicações legais.

A Resolução n. 1.805/2006 foi editada em 28 de novembro de 2006, pelo Conselho Federal de Medicina, com o intuito de regulamentar a prática 
da ortotanásia, autorizando aos médicos sua realização, bem como apresentando diretrizes éticas para instruí-los acerca de como agir nessa situação.

Sua aprovação se deu logo após o caso do ex-governador do Estado de São Paulo, Mário Covas, em 2001, que, ao ser diagnosticado com câncer de meninge, decidiu passar seus últimos dias de vida fora do hospital, sendo tratado apenas com cuidados paliativos. Para tal, Covas utilizou da Lei Estadual n. 10.241, conhecida como Lei Mário Covas, que estabelece em seu Art. 2으, incisos VII, XXIII e XXIV:

2o - São direitos dos usuários dos serviços de saúde no Estado de São Paulo:

$[\ldots]$

VII- consentir ou recusar, de forma livre, voluntária e esclarecida, com adequada informação, procedimentos diagnósticos ou terapêuticos a serem nele realizados;

$[\ldots]$

XXIII- recusar tratamentos dolorosos ou extraordinários para tentar prolongar a vida; e

$[\ldots]$

XXIV- optar pelo local de morte.

De acordo com a Resolução n. 1.805/2006, os médicos devem respeitar os princípios da bioética, particularmente no que tange à autonomia do paciente terminal ou de seu representante, que deve ter conhecimento de suas opções e possibilidades e expressar seu consentimento. Além disso, deve ser observado o princípio da beneficência, procedendo aos cuidados paliativos em prol do bem-estar do paciente. Assim estabelece a resolução:

Art. 1 o É permitido ao médico limitar ou suspender procedimentos e tratamentos que prolonguem a vida do doente em fase terminal, de enfermidade grave e incurável, respeitada a vontade da pessoa ou de seu representante legal.

$\S 1$ O O médico tem a obrigação de esclarecer ao doente ou a seu representante legal as modalidades terapêuticas adequadas para cada situação.

$\S 2$ ○ A decisão referida no caput deve ser fundamentada e registrada no prontuário.

$\S 3$ ó ́́ assegurado ao doente ou a seu representante legal o direito de solicitar uma segunda opinião médica. 
Art. 2으 O doente continuará a receber todos os cuidados necessários para aliviar os sintomas que levam ao sofrimento, assegurada a assistência integral, o conforto físico, psíquico, social e espiritual, inclusive assegurando-Ihe o direito da alta hospitalar.

A mencionada Resolução foi objeto da Ação Civil Pública n. 2007.34.00.014809-3, ajuizada pelo Ministério Público Federal, para declarar sua inconstitucionalidade e ilegalidade em razão da incompetência material do Conselho Federal de Medicina para referir-se à disposição da vida. Então, em sede liminar, o juiz do caso suspendeu a Resolução, considerando a prática de ortotanásia como conduta de homicídio, tipificado no artigo 121 do Código Penal Brasileiro.

Em 2007, o Ministério Público Federal posicionou-se favoravelmente ao Conselho Federal de Medicina, manifestando-se no sentido de que ele é competente para editar a referida resolução, pois esta aborda matéria de ética médica e não conteúdo penal, ratificando não se tratar da regulamentação de uma conduta de homicídio praticada pelo médico. Assim, o juiz do caso julgou improcedente o processo, revogando a medida liminar.

Insta salientar que a Resolução n. 1.805/2006 do CFM está em conformidade com o Código de Ética Médica, que indica que o médico deve evitar a utilização de tratamentos desnecessários aos pacientes acometidos por doenças terminais e incuráveis, bem como atribui ao médico o dever de oferecer a tais pacientes os cuidados paliativos adequados. Dessa forma, apesar de permanecerem dúvidas e adversidades acerca do tema, a prática de ortotanásia foi reconhecida na esfera jurídica em razão da Resolução n. 1.805/2006 do Conselho Federal de Medicina.

Em termos complementares, a Resolução n. 1.995/2012, também editada pelo Conselho Federal de Medicina, regulamenta sobre as diretivas antecipadas de vontade dos pacientes. De acordo com ela, os médicos deverão atender ao disposto nas diretivas antecipadas de vontade, nos casos em que o paciente não puder exprimir suas vontades livremente, ditando, inclusive, que estas prevalecerão sobre quaisquer outros desejos dos familiares e pareceres não médicos. Além disso, os médicos deverão desconsiderar as diretivas antecipadas do paciente caso contrariem os preceitos do Código de Ética Médica. 
Do mesmo modo que a Resolução n. 1.805/2006, a Resolução n. 1.995/2012 também foi objeto de uma Ação Civil Pública ajuizada pelo Ministério Público Federal e foi julgada improcedente, por tratar-se da maneira pela qual o paciente externará sua vontade acerca de quaisquer tratamentos que venha a precisar, não apenas em relação à ortotanásia, assim como porque a matéria regulada faz parte da competência do Conselho Federal de Medicina, pois versa apenas sobre ética médica.

Além das dificuldades com as regulamentações da prática de ortotanásia no complexo da ética médica, existem também possíveis implicações legais relacionadas a esta prática no Brasil, apesar de o Código Penal Brasileiro não ter previsão legal que tipifique a prática.

Subsistem alguns posicionamentos tendentes a amoldar a ortotanásia nos crimes de homicídio privilegiado, omissão de socorro e até de auxílio ao suicídio, previstos, respectivamente, nos artigos 121, §1ㅇ, 135 e 122, todos do Código Penal, sendo este, inclusive, um posicionamento de alguns representantes das Seccionais Ordem dos Advogados do Brasil. Tais crimes consistem em:

Art. 121. Matar alguém:

Pena- reclusão, de seis a vinte anos.

Caso de diminuição de pena.

$\S 1$ o Se o agente comete o crime impelido por motivo de relevante valor social ou moral, ou sob o domínio de violenta emoção, logo em seguida a injusta provocação da vítima, o juiz pode reduzir a pena de um sexto a um terço.

Art. 135. Deixar de prestar assistência, quando possível fazê-lo sem risco pessoal, à criança abandonada ou extraviada, ou à pessoa inválida ou ferida, ao desamparo ou em grave e iminente perigo; ou não pedir, nesses casos, o socorro da autoridade pública:

Pena- detenção, de um a seis meses, ou multa.

Parágrafo único- A pena é aumentada de metade, se da omissão resulta lesão corporal de natureza grave, e triplicada, se resulta a morte. Art. 122-Induzir ou instigar alguém a suicidar-se ou prestar-Ihe auxílio para que o faça:

Pena - reclusão, de dois a seis anos, se o suicídio se consuma; ou reclusão, de um a três anos, se da tentativa de suicídio resulta lesão corporal de natureza grave. 
Não se pode adequar a prática de ortotanásia a nenhum tipo penal e nem considerar a prática como um crime, em respeito aos princípios da legalidade e da anterioridade, previstos no artigo 50, inciso II, da Constituição Federal, e no artigo 1ำ do Código Penal, que estabelecem:

Art. 5ㅇ- $[\ldots]$

II - ninguém será obrigado a fazer ou deixar de fazer alguma coisa senão em virtude de lei (CONSTITUIÇÃO FEDERAL).

Art. 1-- Não há crime sem lei anterior que o defina. Não há pena sem prévia cominação legal (CÓDIGO PENAL).

Para que a prática de ortotanásia configurasse em homicídio ou omissão de socorro, o médico deveria agir com dolo ou intenção de causar a morte do enfermo, o que não ocorre, tendo em vista que, na realização da ortotanásia, a finalidade única do médico é a de preservar o bem-estar e a dignidade do paciente, tratando suas dores e sofrimentos com cuidados paliativos e evitando uma situação de distanásia, de acordo com a vontade do paciente.

Em vista do exposto e diante dos posicionamentos contrários à prática, nota-se que, com a ausência de legislação própria para tratar da prática de ortotanásia, além das Resoluções n. 1.805/06 e n. 1.995/2012 do Conselho Federal de Medicina, os médicos e profissionais da área da saúde enfrentam uma situação de enorme insegurança jurídica, já que não é demonstrada uma certeza de que sua prática não será penalmente punida por algum crime.

\section{DIREITOS HUMANOS E A VIDA DIGNA}

Provocada pelos ideais iluministas e humanistas de fraternidade, igualdade e liberdade, a Declaração Universal dos Direitos Humanos foi criada pela Organização das Nações Unidas após o final da Segunda Guerra Mundial, com o intento de evitar uma Terceira Guerra Mundial, protegendo os direitos fundamentais e a dignidade de toda a humanidade. Para Almeida (1996), os Direitos Humanos são as limitações e ressalvas impostas ao poder político, expressas em declarações e legislações públicas e privadas, que têm o intuito de fazer com que as condições de vida necessárias para que 
todos os seres humanos possam desenvolver sua inteligência, dignidade e consciência, bem como satisfazer suas necessidades materiais e espirituais, sejam respeitadas e materializadas.

Os Direitos Humanos dispõem de atribuições e valores básicos para se obter uma vida digna, relacionando-se com a dignidade da pessoa humana. Assim, protegem a dignidade humana em todos os seus traços, como o respeito à autonomia da vontade, à não coisificação do ser humano e à integridade física, intelectual e moral.

A dignidade da pessoa humana é um princípio fundamental do Estado Democrático de Direito e da proteção aos Direitos Humanos e está prevista no Art. 1ํ, III da Constituição da República Federativa do Brasil de 1988.

Para Sarlet (2006), a dignidade da pessoa humana pode ser definida como uma característica inerente e distintiva presente em todos os seres humanos, fazendo-os merecedores de respeito e consideração pelo Estado e pela comunidade, implicando um complexo de direitos e deveres fundamentais que assegurem o indivíduo contra todo e qualquer ato de cunho degradante e desumano, bem como garantam-Ihe condições mínimas de existência para uma vida saudável, propiciando e promovendo sua participação ativa e corresponsável pelo destino de sua própria vida e da vida em comunhão com as demais pessoas.

O conceito de dignidade tem por sentido a não coisificação do ser humano, tratando e reconhecendo os seres humanos como pessoas racionais, autônomas, com personalidades diferentes e individuais, considerando que são insubstituíveis e possuem seu próprio valor, que é imensurável. Acerca disso, Kant (2007, p. 77) afirma que:

[...] A razão relaciona, pois, cada máxima da vontade concebida como legisladora universal com todas as outras vontades e com todas as ações para conosco mesmos, e isto não em virtude de qualquer outro móbil prático ou de qualquer vantagem futura, mas em virtude da ideia da dignidade de um ser racional que não obedece a outra lei senão àquela que ele mesmo simultaneamente dá. No reino dos fins tudo tem ou um preço ou uma dignidade. Quando uma coisa tem um preço, pode-se pôr em vez dela qualquer outra como equivalente; mas quando uma coisa está acima de todo o preço, e portanto não permite equivalente, então tem ela dignidade. 
Apresentando-se como um atributo inerente a todos os seres humanos, a dignidade da pessoa humana compreende as noções de direito à vida, à liberdade, à autonomia da vontade e à integridade física e moral.

O direito à liberdade está previsto no Art. 5ㅇ, caput e inciso II da Constituição Federal de 1988, bem como no artigo III da Declaração Universal dos Direitos Humanos. Este direito garante que o indivíduo aja de forma independente e sem restrições, exceto as advindas de lei, relacionando-se diretamente com a autonomia, que, por sua vez, seria a autodeterminação do agente, ou seja, a capacidade de agir de acordo com suas vontades e de realizar decisões e escolhas acerca de sua vida. Cabe dizer que a conexão entre a autonomia e a dignidade existe de forma que só há vida digna se houver respeito à autonomia.

O direito dos pacientes terminais decidirem acerca dos tratamentos e intervenções médicas a serem realizadas em seu corpo deve existir, para que a autonomia da vontade e a liberdade destes sejam respeitadas. Em virtude disso, é facultada a utilização das diretivas antecipadas de vontade, ao passo que o direito à vida aqui tratado, tutelado no Art. 5으, caput, da Constituição Federal, e no Art. III da Declaração Universal dos Direitos Humanos, é um direito fundamental e inerente a todos.

Seu conceito estende-se à noção de existência, que a todos devem ser garantidas as condições mínimas para viver com qualidade e dignidade. Canotilho (2007, p. 447) afirma que: "[...] num sentido normativo, o direito à vida significa, primeiro e acima de tudo, direito de não ser morto, de não ser privado da vida.". Sua garantia faz-se necessária, pois a vida não pode ser substituída e sua disposição não é reversível, sendo então um direito indisponível.

O direito à vida, ao mesmo tempo em que garante que as pessoas se mantenham vivas, impede que elas disponham da vida, sua ou de outrem, independentemente da qualidade desta. Nesse sentido, o ordenamento jurídico brasileiro proíbe a eutanásia, o homicídio e o aborto, excepcionando-se as situações de legítima defesa, no caso do homicídio, e as situações de estupro ou risco para a vida da mãe, no caso do aborto. Tais proibições permitem o entendimento de que os próprios detentores do direito não podem exercê-lo ou renunciá-lo livremente. 
Nesse seguimento, discute-se acerca da colisão entre a aplicação dos direitos à vida, à liberdade e à dignidade humana, que possuem o poder de limitar um ao outro, como é o caso da proibição à eutanásia, em que os direitos à liberdade individual e à dignidade humana são cerceados em prol do direito à vida. Diante desse conflito, um juízo de ponderação capaz de analisar o caso concreto com suas características, observado o princípio da proporcionalidade e seus elementos de necessidade e adequação, torna possível sua resolução, já que não existe um grau de hierarquia determinado entre estes direitos. Contudo vale dizer que direitos mais abrangentes os tornam mais relevantes, sendo este o caso da dignidade da pessoa humana. Acerca disso, Gilmar Mendes (2012, p. 348) afirma que:

[...] Embora o texto constitucional brasileiro não tenha privilegiado especificamente determinado direito, na fixação das cláusulas pétreas (CF, art. 60, § 4ㅇ), não há dúvida de que, também entre nós, os valores vinculados ao princípio da dignidade da pessoa humana assumem peculiar relevo (CF, art. 1으, III). Assim, devem ser levados em conta, em eventual juízo de ponderação, os valores que constituem inequívoca expressão desse princípio (inviolabilidade de pessoa humana, respeito à sua integridade física e moral, inviolabilidade do direito de imagem e da intimidade).

Nessa perspectiva, permitir que o paciente terminal decida por não se submeter a tratamentos inúteis e desgastantes, recebendo os cuidados paliativos, significaria respeitar o direito à liberdade e autonomia deste indivíduo, ainda que, para evitar uma situação de sobrevida e distanásia involuntária, o direito à vida na percepção estritamente biológica seja limitado, observando especialmente a dignidade da pessoa humana. Essa situação também demonstraria um equilíbrio entre os princípios da sacralidade da vida e da qualidade de vida, que, conforme Schramm (2009), significam, respectivamente, a não intervenção na vida humana, respeitando o ciclo natural da vida e a intervenção na vida humana com a intenção de promover a qualidade e o bem-estar, desde que não prejudique terceiros.

Sucessivamente, tratando-se do respeito aos direitos humanos e fundamentais dos indivíduos, sabe-se que foi delegada ao Estado a atribuição de protegê-los e de assegurar o bem-estar social. Ao mesmo tempo, o Estado deve respeitar os direitos e as liberdades individuais, o que limita 
relativamente sua atuação na sociedade, de modo que sua intervenção na vida privada se justificaria apenas para proteger algum direito ou evitar que terceiros sejam prejudicados. Assim, o interesse do Estado em intervir na vida do enfermo terminal deve se dar para garantir que não apenas a vida como elemento biológico se mantenha, prolongando tratamentos inúteis a situações inconvertíveis, mas garantir o direito a uma vida com qualidade e dignidade, respeitando igualmente sua autonomia.

É importante salientar, neste rol de argumentos, que na ortotanásia não há uma disposição da vida em si, pois neste caso a vida do paciente está sendo extinta em razão da enfermidade que ele possui, o processo natural de morte já está instalado e não há possibilidade alguma de recuperação, pelo que seria desumano submeter o paciente a tratamentos desgastantes e invasivos sem um propósito, além de desrespeitar sua dignidade e autonomia. Ademais, não se trata de direito de morrer, que significa intervir de alguma forma para ocasionar a morte, mas sim direito de decidir como se despedir do mundo e das pessoas ao redor. Nesse sentido, Pessini (2004, p. 226) defende que "[...] no fundo, a ortotanásia é para o doente morrer saudavelmente, cercado de amor e carinho, amando e sendo amado enquanto se prepara para o mergulho final no amor que não tem medida e que não tem fim".

Diante da conexão entre a dignidade da pessoa humana, direito à liberdade e direito à vida, considera-se digna a vida com qualidade e bem-estar, que possui suas vontades respeitadas pelo Estado e pelos outros indivíduos, bem como que não seja submetida a danos físicos e morais. A ortotanásia, então, quando praticada de forma correta, respeitando os princípios e requisitos de sua aplicação, é amparada pela dignidade humana ao proporcionar ao enfermo uma vida digna - e uma morte digna - até que o processo de falecimento se finalize, respeitando a autonomia da vontade do paciente.

\section{CONSIDERAÇÕES FINAIS}

O objetivo principal do presente artigo era discutir acerca da visão dos Direitos Humanos sobre a prática da ortotanásia, com a finalidade de 
compreender se é um meio digno de morte aos pacientes acometidos por enfermidade terminal, bem como discutir se o ordenamento jurídico brasileiro recepcionou essa prática e determinar quais as suas possíveis implicações legais.

De acordo com o exposto acima, percebe-se que, apesar de o ordenamento jurídico pátrio não proibir a prática da ortotanásia, não sendo tipificada como um crime pelo Código Penal, alguns doutrinadores tendem a encaixar a prática nos crimes de omissão de socorro, homicídio e auxílio ao suicídio. Dessa forma, verificou-se que a escassa regulamentação - limitada às Resoluções n. 1.805/2006 e n. 1.995/2012 do Conselho Federal de Medicina - gera uma enorme insegurança jurídica aos médicos e profissionais de saúde para realizar a prática, já que não têm certeza de que não incidirão nas penas dos crimes anteriormente citados.

Observa-se também que a prática de ortotanásia tem resguardo nos Direitos Humanos, especialmente no que concerne à dignidade da pessoa humana, visto que a respeita em todos os seus traços, como a autonomia da vontade, o direito à liberdade e o direito à vida com qualidade, bem como a integridade física e moral do paciente, deixando de submeter o enfermo terminal a tratamentos desgastantes e ineficazes e a uma vida precária ou até uma sobrevida, conforme a vontade do paciente.

Por fim, a pesquisa permitiu compreender que a ortotanásia pode ser reconhecida como um fim digno aos enfermos terminais, pois possibilita que estes decidam como vão partir, proporcionando qualidade de vida, conforto e bem-estar em seus últimos momentos de vida, desde que feita corretamente, de acordo com os princípios da bioética e do biodireito e dentro dos requisitos, em respeito aos direitos humanos.

\section{REFERÊNCIAS}

ACADEMIA NACIONAL DE CUIDADOS PALIATIVOS [ANCP]. Manual de cuidados paliativos. Rio de Janeiro: Diagraphic, 2009.

ALMEIDA, Aline Mignon. Bioética e Biodireito. Rio de Janeiro: Lumen Juris, 2000.

ALMEIDA, Fernando Barcellos. Teoria Geral dos Direitos Humanos. Porto Alegre: Sérgio Antônio Fabris, 1996. 
BRASIL. Ministério Público Federal. Ação Civil Pública n. 001039- 86.2013.4.01.3500. Brasília-DF, 2013.

BRASIL. Ministério Público Federal. Ação Civil Pública n. 2007.34.00.014809-3. Brasília-DF, 2010.

BRASIL. Constituição da República Federativa do Brasil. Brasília, DF: Senado Federal, 1988.

BRASIL. Código Penal Brasileiro. Decreto-Lei n. 2.848, de 7 de dezembro de 1940. Brasília, DF, 1940

CABETTE, Eduardo Luiz Santos. Eutanásia e Ortotanásia: comentários à Resolução 1.805/06 CFM. Aspectos éticos e jurídicos. 2a reimp. Curitiba: Juruá, 2013.

CANOTILHO, J. J. Gomes; MOREIRA, Vital. Constituição da República Portuguesa anotada: artigos 1으 a 107. São Paulo: Revista dos Tribunais, 2007. p. 447. v. 1

CONSELHO FEDERAL DE MEDICINA [CFM]. Resolução n. 1.805, de 28 de novembro de 2006. Brasília, DF, 2006.

CONSELHO FEDERAL DE MEDICINA [CFM]. Resolução n. 1.995, de 31 de agosto de 2012. Brasília, DF, 2012

CONSELHO FEDERAL DE MEDICINA. Código de Ética Médica. Resolução n. 2.217, de 27 de setembro de 2018. Brasília, DF, 2018.

DINIZ, Maria Helena. O estado atual do Biodireito. 4. ed. São Paulo: Saraiva, 2007.

DINIZ, Maria Helena. O estado atual do Biodireito. 7. ed. São Paulo: Saraiva, 2010.

GONÇALVES, Carlos Roberto. Direito Civil Brasileiro: Direito das Sucessões, 12. ed. São Paulo: Editora Saraiva, 2019. v. 7.

KANT, Immanuel. Fundamentação da metafísica dos costumes. Tradução de Paulo Quintela. Lisboa: Edições 70, 2007.

LOPES, A. C.; LIMA, C. A. S.; SANTORO, L. F. Eutanásia, Ortotanásia e Distanásia: aspectos médicos e jurídicos. 3. ed. Rio de Janeiro: Atheneu, 2018.

MARQUES, Heitor Romero; MANFROI, José; CASTILHO, Maria Augusta; NOAL, Mirian Lange. Metodologia da pesquisa e do trabalho científico. 4. ed. Campo Grande: UCDB, 2014. 
MENDES, Gilmar Ferreira; BRANCO, Paulo Gustavo Gonet. Curso de direito constitucional. 7. ed. São Paulo: Saraiva, 2012.

ORGANIZAÇÃO DAS NAÇÕES UNIDAS [ONU]. Declaração Universal dos Direitos Humanos, 1948.

PESSINI, Leo. Eutanásia: por que abreviar a vida? São Paulo: São Camilo, 2004.

REICH, Warren T. Encyclopedia of bioethics. London: Simon \& Schuster Macmillan, 1995.

SÃO PAULO (Estado). Lei n. 10.241, de 17 de março de 1999. Dispõe sobre os direitos dos usuários dos serviços e das ações de saúde no Estado. São Paulo, 1999.

SARLET, Ingo Wolfgang. Dignidade da pessoa humana e direitos fundamentais na Constituição Federal de 1988. 4. ed. Porto Alegre: Livraria do Advogado, 2006.

SCHRAMM, Fermin Roland. O uso problemático do conceito 'vida' em bioética e suas interfaces com a práxis biopolítica e os dispositivos de biopoder. Revista Bioética, Brasília-DF, v. 17, n. 3, 2009.

VIEIRA, Mônica Silveira. Eutanásia: humanizando a visão jurídica. Curitiba: Juruá, 2009. 
